\title{
Multiparametric Functional Magnetic Resonance Imaging for Evaluating Renal Allograft Injury
}

\author{
Yuan Meng Yu, BS ${ }^{1}$, Qian Qian $\mathrm{Ni}, \mathrm{PhD}^{2}$, Zhen Jane Wang, $\mathrm{MD}^{3}$, Meng Lin Chen, $\mathrm{BS}^{4}$, \\ Long Jiang Zhang, MD, PhD² \\ ${ }^{1}$ Department of Medical Imaging, Jinling Hospital, Clinical School of Southern Medical University, Nanjing, China; ${ }^{2}$ Department of Medical \\ Imaging, Jinling Hospital, Medical School of Nanjing University, Nanjing, China; ${ }^{3}$ Department of Radiology and Biomedical Imaging, University \\ of California San Francisco, San Francisco, CA, USA; ${ }^{4}$ Medical Imaging Teaching and Research Office, Nanfang Hospital, Southern Medical \\ University, Guangzhou, China
}

Kidney transplantation is the treatment of choice for patients with end-stage renal disease, as it extends survival and increases quality of life in these patients. However, chronic allograft injury continues to be a major problem, and leads to eventual graft loss. Early detection of allograft injury is essential for guiding appropriate intervention to delay or prevent irreversible damage. Several advanced MRI techniques can offer some important information regarding functional changes such as perfusion, diffusion, structural complexity, as well as oxygenation and fibrosis. This review highlights the potential of multiparametric MRI for noninvasive and comprehensive assessment of renal allograft injury.

Keywords: Multiparametric magnetic resonance imaging; Functional MRI; Kidney transplantation; Allograft fibrosis; Allograft dysfunction

\section{INTRODUCTION}

Kidney transplantation is the treatment of choice for patients with end-stage renal disease, providing superior outcomes in terms of survival, quality of life, and costeffectiveness when compared to dialysis (1). In 2015, over 18000 adult and pediatric kidney transplantation procedures, including multi-organ transplantation, were performed in the United States. Over the past 5 years, approximately 5000-6000 kidney transplantation procedures have been performed in China each year, and the number continues to rise $(2,3)$. Despite the advances in surgical techniques and immunosuppressive therapies, the long-term

Received August 8, 2018; accepted after revision December 19, 2018.

Corresponding author: Long Jiang Zhang, MD, PhD, Department of Medical Imaging, Jinling Hospital, Medical School of Nanjing University, Nanjing, Jiangsu 210002, China.

- Tel: (8625) 80860114 - Fax: (8625) 80860114

- E-mail: kevinzhlj@163.com

This is an Open Access article distributed under the terms of the Creative Commons Attribution Non-Commercial License (https://creativecommons.org/licenses/by-nc/4.0) which permits unrestricted non-commercial use, distribution, and reproduction in any medium, provided the original work is properly cited. outcome of renal allografts has not improved over the last two decades. This is due, in part, to chronic allograft injury, the leading cause of renal allograft failure. Chronic allograft injury is characterized by tubular atrophy, interstitial fibrosis, glomerulosclerosis, and vascular occlusive changes that include dropout of the peritubular capillaries, leading to progressive allograft dysfunction. Early detection of allograft injury is essential to guide treatment and to delay or prevent irreversible damage to the allograft $(4,5)$.

Current methods for assessing allograft injury have significant limitations. Measurement of serum creatinine level and the estimated glomerular filtration rate (eGFR) are the most commonly used methods for monitoring allograft function. However, they are known to have poor predictive value for allograft injury. By the time the serum creatinine has increased or the eGFR has reduced, the degree of allograft injury may have already become advanced and irreversible (6). There are also multiple imaging techniques for evaluating renal allografts. Ultrasonography is useful for detecting the urologic and vascular etiologies underlying allograft dysfunction. Computed tomography (CT) is commonly utilized for evaluating perinephric, vascular, and urinary tract complications involving the allograft. However, 
none of these modalities can reliably diagnose allograft injury. In addition, $\mathrm{CT}$ is associated with the risk of ionizing radiation, and the intravenous iodinated CT contrast agent might lead to contrast-induced nephropathy in patients with reduced renal function (7). As a result, allograft biopsy remains the method of choice to diagnose allograft injury and to differentiate among the different etiologies, despite its limitations such as invasiveness, sampling errors, and the risk of complications such as bleeding, infection, and even graft loss (8). Thus, there is an urgent need to develop

Table 1. MRI Techniques Used for Evaluation of Kidney Allograft Injury

\begin{tabular}{|c|c|c|c|c|}
\hline MRI Sequence & Principle & Advantages & Disadvantage & Application \\
\hline $\begin{array}{l}\text { Conventional } \\
\text { DWI }\end{array}$ & $\begin{array}{l}\text { Quantifies displacement } \\
\text { of water molecules } \\
\text { to evaluate tissue } \\
\text { microstructure }\end{array}$ & $\begin{array}{l}\text { Choice of b-values is easy } \\
\text { Shorter scan time }\end{array}$ & $\begin{array}{l}\text { Motion-related artifacts } \\
\text { Information of micro- } \\
\text { perfusion and water } \\
\text { molecules diffusion cannot } \\
\text { be separated }\end{array}$ & $\begin{array}{l}\text { Monitor allograft function } \\
\text { Evaluate interstitial fibrosis } \\
\text { and tubular atrophy }\end{array}$ \\
\hline IVIM DWI & $\begin{array}{l}\text { Separately estimates } \\
\text { tissue micro-perfusion } \\
\text { and water molecules } \\
\text { diffusion to assess tissue } \\
\text { microstructure }\end{array}$ & $\begin{array}{l}\text { Evaluates micro-perfusion } \\
\text { and water diffusion } \\
\text { separately }\end{array}$ & $\begin{array}{l}\text { Motion-related artifacts } \\
\text { Choice of b-values is not } \\
\text { standardized }\end{array}$ & $\begin{array}{l}\text { Monitor allograft function } \\
\text { Evaluate interstitial fibrosis } \\
\text { and tubular atrophy }\end{array}$ \\
\hline DTI & $\begin{array}{l}\text { Investigates directionality } \\
\text { of water molecular motion } \\
\text { due to anisotropy of tissue }\end{array}$ & $\begin{array}{l}\text { Accounts for directionality } \\
\text { of water diffusion, such as } \\
\text { along renal tubules }\end{array}$ & $\begin{array}{l}\text { Chemical shifts and } \\
\text { susceptibility image } \\
\text { artifacts } \\
\text { FA is non-specific for } \\
\text { pathophysiological change }\end{array}$ & $\begin{array}{l}\text { Monitor allograft function } \\
\text { Evaluate interstitial fibrosis } \\
\text { and tubular atrophy }\end{array}$ \\
\hline DKI & $\begin{array}{l}\text { Calculates non-gaussian } \\
\text { behavior of water diffusion } \\
\text { to more accurately reflect } \\
\text { tissue microstructural } \\
\text { complexity }\end{array}$ & $\begin{array}{l}\text { Accounts for non-gaussian } \\
\text { motion of water molecular }\end{array}$ & Low SNR & $\begin{array}{l}\text { Evaluate interstitial fibrosis } \\
\text { and tubular atrophy }\end{array}$ \\
\hline BOLD & $\begin{array}{l}\text { Quantifies tissue } \\
\text { oxygenation based on } \\
\text { paramagnetic properties of } \\
\text { blood deoxyhemoglobin }\end{array}$ & $\begin{array}{l}\text { Evaluates tissue oxygen } \\
\text { bioavailability }\end{array}$ & $\begin{array}{l}\text { R2* cannot distinguish } \\
\text { causes of oxygenation } \\
\text { changes }\end{array}$ & Monitor allograft function \\
\hline ASL & $\begin{array}{l}\text { Quantifies perfusion by } \\
\text { selectively labeling } \\
\text { inflowing blood }\end{array}$ & $\begin{array}{l}\text { Evaluates tissue perfusion } \\
\text { without exogenous } \\
\text { contrast materials }\end{array}$ & $\begin{array}{l}\text { Low SNR } \\
\text { Perfusion is affected by } \\
\text { other factors such as } \\
\text { orientation of imaging } \\
\text { slice, and renal cortical } \\
\text { T1 values }\end{array}$ & Monitor allograft perfusion \\
\hline MRE & $\begin{array}{l}\text { Quantifies viscoelastic } \\
\text { properties of tissues } \\
\text { based on their response } \\
\text { to external mechanical } \\
\text { vibration }\end{array}$ & Quantifies tissue fibrosis & $\begin{array}{l}\text { Kidney stiffness } \\
\text { measurement is } \\
\text { multifactorial, and is affect } \\
\text { by renal perfusion }\end{array}$ & Quantify renal fibrosis \\
\hline MTI & $\begin{array}{l}\text { Evaluates macromolecule } \\
\text { (i.e., collagen) based on } \\
\text { interactions of protons } \\
\text { from free water and } \\
\text { macromolecules }\end{array}$ & Quantifies tissue fibrosis & $\begin{array}{l}\text { MTR is affected by structural } \\
\text { and functional alterations } \\
\text { besides fibrosis } \\
\text { Low SNR }\end{array}$ & Quantify renal fibrosis \\
\hline
\end{tabular}

$\mathrm{ASL}=$ arterial spin labeling, BOLD = blood oxygen-level-dependent, DKI = diffusion kurtosis imaging, DTI = diffusion tensor imaging, DWI = diffusion-weighted imaging, FA = fractional anisotropy, IVIM = intravoxel incoherent motion, MRE = magnetic resonance elastography, MTI = magnetization transfer imaging, MTR = magnetization transfer ratio, SNR = signal-to-noise ratio 
noninvasive and accurate approaches for diagnosing renal graft injury to guide timely intervention.

Magnetic resonance imaging (MRI) has shown promise in providing morphological, microstructural, and functional characterization of renal allografts. MRI does not use ionizing radiation and allows repeated imaging during follow-up of patients with renal allografts $(9,10)$. Various MRI techniques have been utilized to interrogate several microstructural and functional parameters in renal allografts (Table 1). This review highlights the clinical value of multiparametric MRI as a noninvasive and comprehensive modality for early diagnosis and longitudinal monitoring of renal allograft injury, and the possibility of using multiparametric MRI in predicting long-term renal allograft outcome.

\section{Diffusion-Weighted Imaging}

Diffusion-weighted imaging (DWI) is a noninvasive method for quantifying the Brownian motion of water molecules in tissues and can provide information regarding tissue microstructure. While DWI was initially used primarily for diagnosing acute stroke, there has been increasing work on the use of DWI for tissue characterization and functional assessment of abdominal organs including the kidneys (11).

The apparent diffusion coefficient (ADC) values for tissues can be derived from DWI data using monoexponential fitting. The $A D C$ values are influenced by multiple factors such as cellularity and the presence of macromolecules. Lower ADC values are indicative of restricted diffusion of water molecules. Several studies have reported that the $A D C$ values are higher in the cortex than the medulla in renal allografts and have suggested that this was a result of the higher blood flow in the cortex and restricted watermolecule diffusion in the medulla $(12,13)$. Other studies, however, have shown virtually identical cortical and medullary $A D C$ values in renal allografts $(14,15)$. The reason for the discrepancy is uncertain, but it may be related to the interval between MRI and kidney transplantation, different imaging strategies, and allograft function status. Meanwhile, other studies have demonstrated a correlation between ADC values and renal allograft function $(16,17)$. For example, Palmucci et al. (17) found that mean allograft $A D C$ values in patients with creatinine clearance $>60 \mathrm{~mL} /$ min were higher than those in patients with creatinine clearance $<30 \mathrm{~mL} / \mathrm{min}$, suggesting that $A D C$ values could be used to predict renal function. Furthermore, several studies demonstrated that stability in allograft ADC level was associated with stable renal function during the followup period after transplantation $(15,18)$.

\section{Intravoxel Incoherent Motion DWI}

In biologic tissues, the intravoxel incoherent motion (IVIM) of water molecular includes both diffusion of water and microcirculation of blood in the capillary network (perfusion). Conventional DWI using a monoexponential fit model to derive the total $A D C\left(A D C_{T}\right)$ cannot separate the water diffusion from capillary perfusion. In contrast, IVIMDWI using a biexponential fit model can separately estimate the tissue capillary perfusion. Specifically, biexponential fitting can be performed to obtain the pure diffusion $\operatorname{ADC}\left(A D C_{D}\right)$, the pseudo-perfusion $A D C\left(A D C_{p}\right)$, which is mainly determined by the much faster microcirculation and perfusion, and the perfusion fraction $\left(F_{p}\right)$, which represents the fractional volume of capillary blood flowing in each voxel $(19,20)$.

An early study showed that $F_{p}$ was reduced in renal allografts with acute rejection (AR), suggesting the potential utility of IVIM-DWI in noninvasive monitoring of allograft injury (12). However, AR and acute tubular necrosis (ATN) of the allografts appear to show similar alterations in IVIM-DWI metrics (13). Recently, Xie et al. (21) applied reduced field of view IVIM-DWI, which has fewer artifacts and distortion and higher image in-plane resolution, to evaluate renal allografts. In that study, $F_{p}$ showed the best performance in evaluating graft function when compared with $A D C_{D}$ and $A D C_{T}$, with cortical $F_{P}$ having a specificity of $66.7 \%$ and sensitivity of $97.1 \%$ for predicting a decline in allograft function (21). In addition, Sulkowska et al. (22) observed that IVIM diffusion parameters may not be as early or as specific as to allow for the prediction of future renal function decline of allografts; however, there was a declining trend toward diffusion values, especially cortical $F_{p}$, with a decrease in allograft function. Therefore, as allograft injury progresses, allograft perfusion might be reduced earlier and affected more than water-molecule diffusion in the cortex (Fig. 1).

\section{Diffusion Tensor Imaging}

Since DWI only measures the diffusion motion of water molecules in the direction of diffusion-sensitive gradient fields, diffusion motion in other directions cannot be 

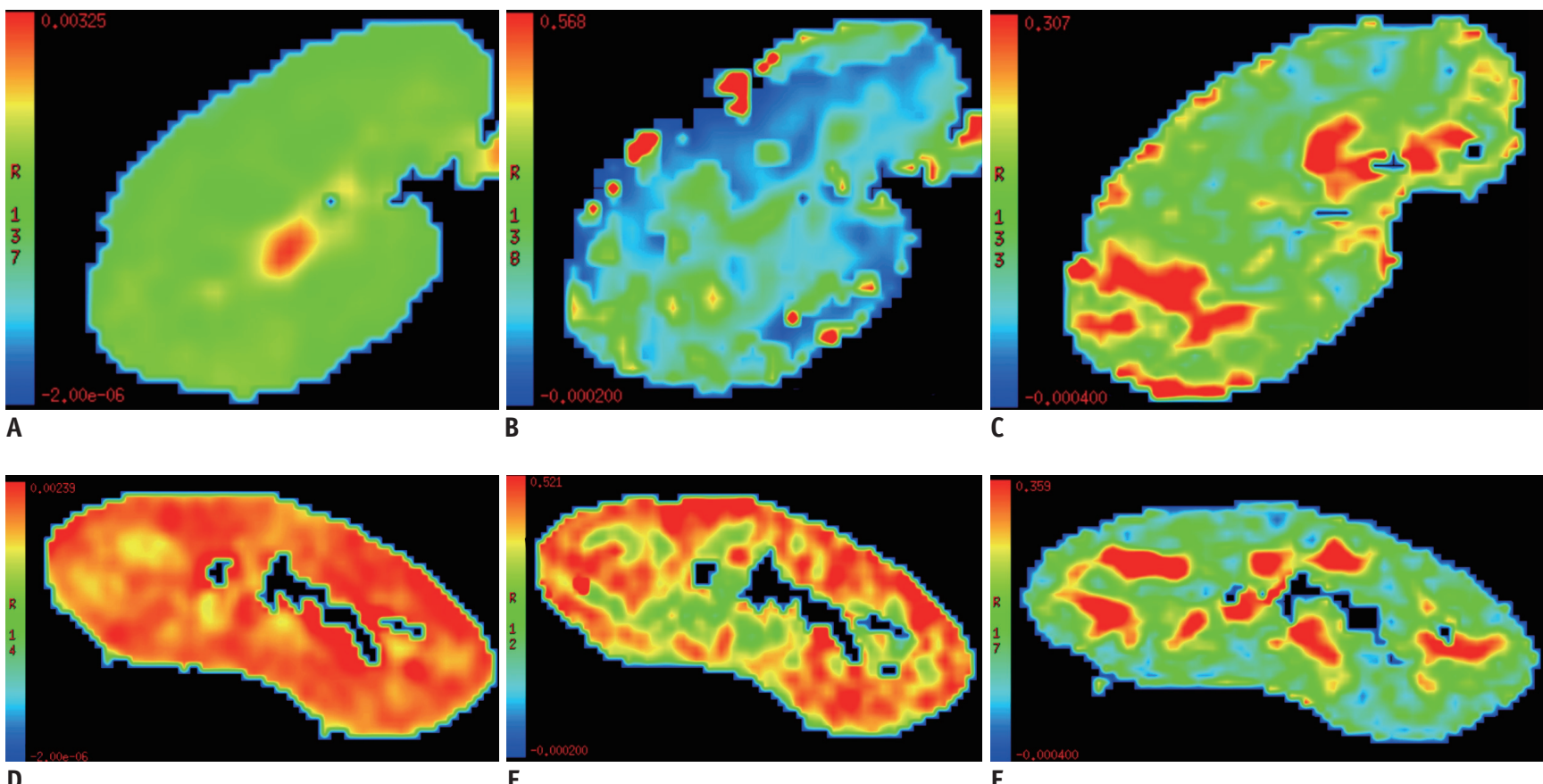

Fig. 1. Comparison of diffusion images $\left(A D C_{T}, F_{P}\right.$, and $F A$ color-coded maps) between patients with poor and good renal allograft function.

Top images (A-C): $A D C_{T}$ map (A), $F_{p}$ map (B), and FA map (C) of 18-year-old male with poor allograft function 1 year after transplantation (eGFR $\left.=20 \mathrm{~mL} / \mathrm{min} / 1.73 \mathrm{~m}^{2}\right)$. Bottom images (D-F): $A D C_{T}$ map $(\mathbf{D}), F_{\mathrm{p}}$ map $(\mathbf{E})$, and $\mathrm{FA}$ map $(\mathbf{F})$ of 35-year-old woman with good allograft function 14 months after transplantation ( $\mathrm{eGFR}=100 \mathrm{~mL} / \mathrm{min} / 1.73 \mathrm{~m}^{2}$ ). Lower $A D C_{\mathrm{T}}, \mathrm{F}_{\mathrm{p}}$, and $\mathrm{FA}$ values were obtained in allograft with poor function. $A D C=$ apparent diffusion coefficient, $A D C_{T}=$ total $A D C$, eGFR $=$ estimated glomerular filtration rate, $F A=$ fractional anisotropy, $F_{p}=$ perfusion fraction

detected. In contrast, an extension of DWI known as diffusion tensor imaging (DTI) measures the diffusion of water molecules in all directions. Specifically, DTI is acquired with diffusion gradients oriented in different directions, and by signal averaging these images to achieve a higher signal-to-noise ratio (SNR). This technique not only quantifies the freedom of water molecules to diffuse, but also calculates the preferential directions of diffusion. For example, the diffusion of water molecules along the direction of the renal medulla tubules is faster. The fractional anisotropy (FA) is used to evaluate the extent to which the diffusion exhibits a preference for direction, with values ranging from 0 to 1 (23). Based on these principles, DTI may be a promising method for detecting renal allograft pathologies such as tubular atrophy, interstitial fibrosis, and cellular infiltration, all of which involve disturbed kidney architecture and microstructure (24).

Studies in human kidneys have shown that the renal medulla has higher FA than the cortex, due to the radial orientation of vessels, tubules, and collecting ducts in the renal medulla $(25,26)$. Several studies have reported decreased FA values with allograft injury, such as AR, ATN, ischemia reperfusion injury, and immunological reactions, indicating allograft microstructure destruction (Fig. 2) (2729). While some investigators did not find FA to be specific for allograft pathology $(29,30)$, others have shown that the medullary and cortical FA values were inversely correlated with the Banff scores that determined cellular rejection and chronicity, such as tubulitis and interstitial inflammation $(31,32)$. Furthermore, the highly oriented microstructure in the renal medulla results in a strong diffusion preference. Hueper et al. (33) speculated that disturbed allograft architecture changes might influence directed diffusion (FA) before global diffusion (ADC). The combination of FA and $A D C$ analysis may allow detailed assessment of renal function changes related to allograft injury $(34,35)$. Taken together, these findings suggest that DTI is a promising tool for detecting allograft pathology noninvasively.

\section{Diffusion Kurtosis Imaging}

Diffusion kurtosis imaging (DKI) extends the conventional DTI model by considering the non-gaussian behavior of water molecules in biological systems and can potentially provide more precise and sensitive measures of microstructural complexity and diffusional heterogeneity. 

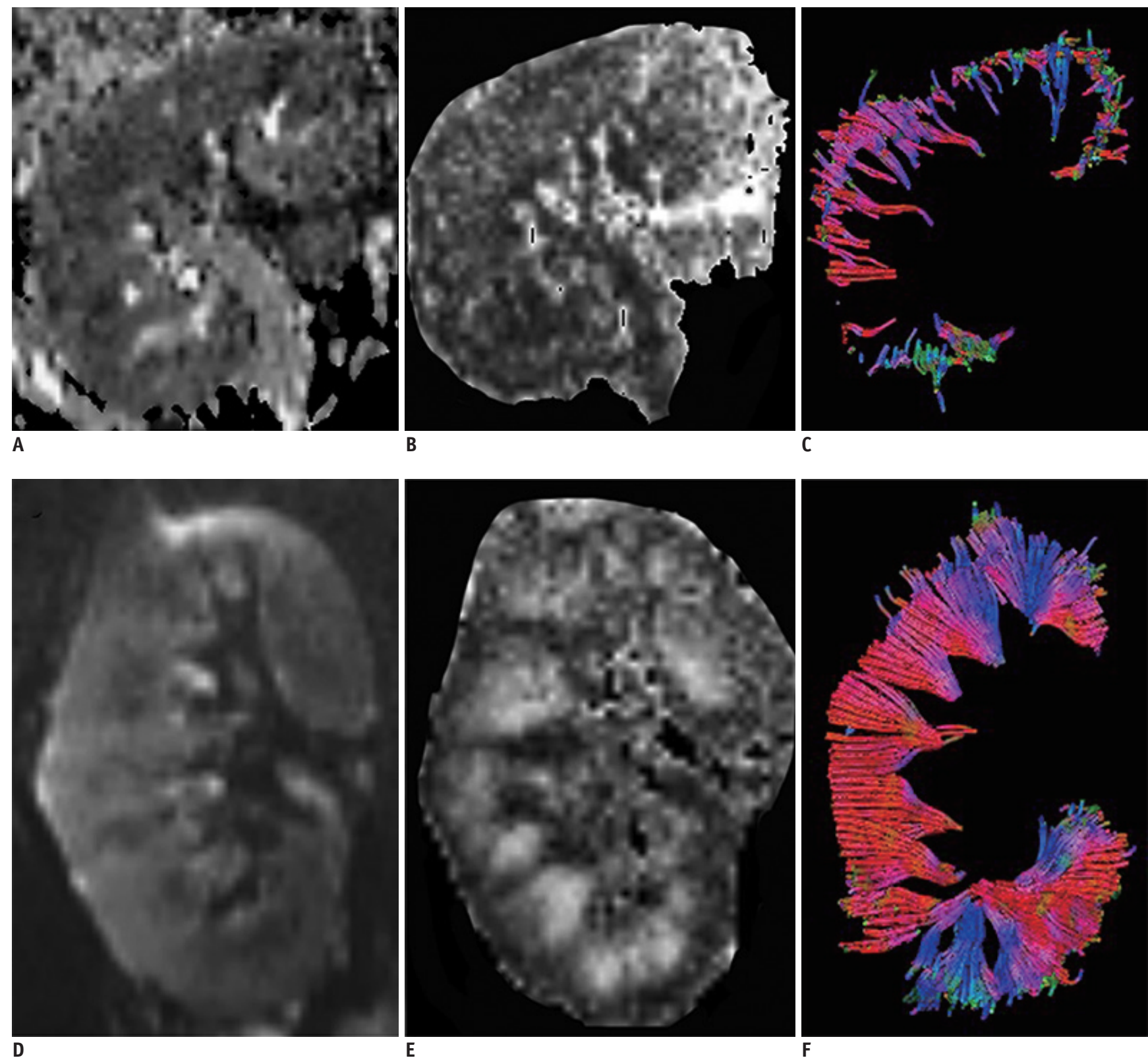

Fig. 2. Comparison of diffusion tensor images (b0 images, FA maps, and whole-kidney tractography images) between patients with poor renal allograft function and those with and good renal allograft function.

Top images (A-C): b0 image (A), FA map (B), and whole-kidney tractography image (C) of 28-year-old woman with poor allograft function (eGFR $=10 \mathrm{~mL} / \mathrm{min} / 1.73 \mathrm{~m}^{2}$ ). Bottom images (D-F): b0 image (D), FA map (E), and whole-kidney tractography image (F) of 22-year-old man with good allograft function (eGFR $=99 \mathrm{~mL} / \mathrm{min} / 1.73 \mathrm{~m}^{2}$ ) (Image courtesy of Wenjun Fan, Lihua Chen, Wen Shen. Department of Radiology, Tianjin First Center Hospital, China).

DKI requires at least $3 b$-values, and the maximum b-value is greater than the b-value required for DWI. In addition to the standard DTI metrics such as the mean diffusivity and FA, DKI can provide metrics related to the diffusional kurtosis, such as mean kurtosis (MK, apparent kurtosis coefficient averaged over all directions), radial kurtosis ( $\kappa_{\perp}$, kurtosis along the radial direction), and axial kurtosis $\left(\kappa_{\|}\right.$, kurtosis along the axial direction) (Fig. 3). Among these metrics, the principal one derived from DKI is MK, which is thought to be an index of microstructural complexity. The larger the MK values are, the more complicated the structure is, and the higher degree of diffusion restriction the nongaussian distribution of water molecules is subjected to. However, there are also many factors that can cause errors in kurtosis values. These include an inhomogeneous T2 relaxation time, gradient pulse duration effects, imaging 


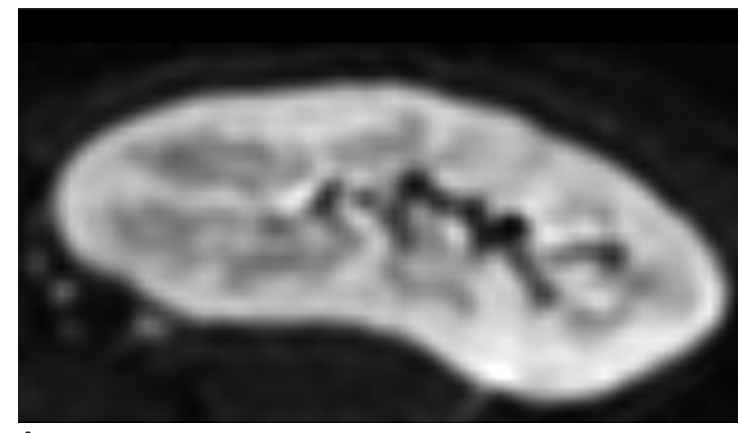

A

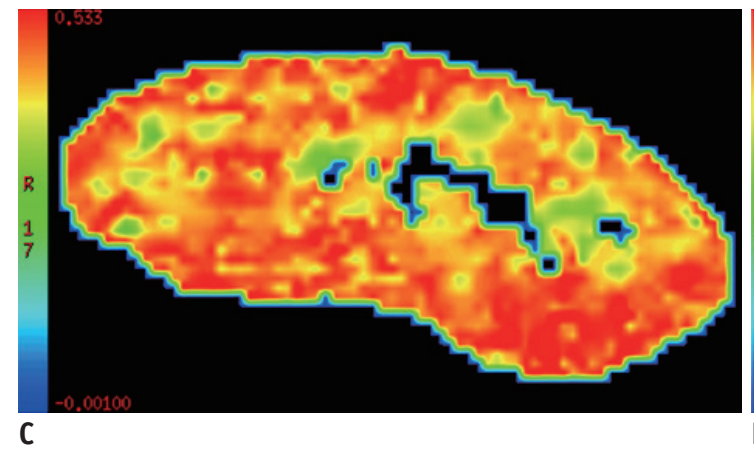

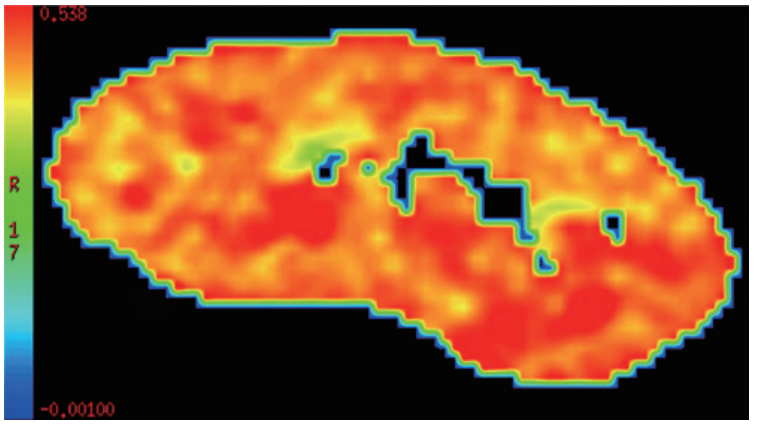

B

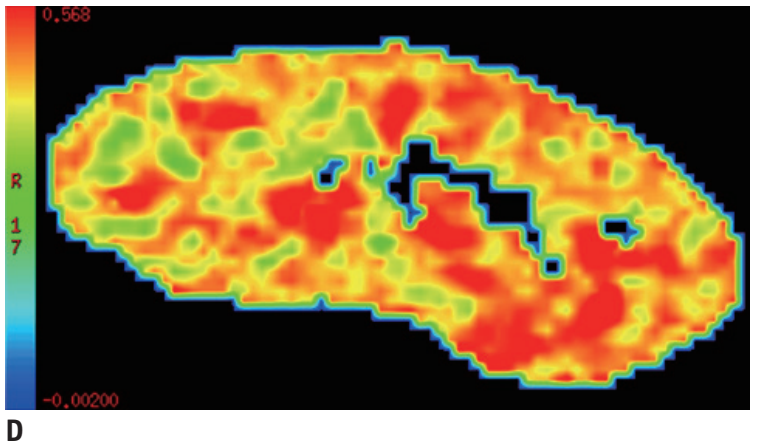

Fig. 3. DKI images and MK, $\kappa_{\|}$, and $\kappa_{\perp}$ color-coded maps of 35-year-old woman with good renal allograft function (eGFR = 100 $\mathrm{mL} / \mathrm{min} / 1.73 \mathrm{~m}^{2}$ ). DKI images (A) with b-value of $0 \mathrm{~s} / \mathrm{mm}^{2}$ and MK maps (B) of renal allograft. C, D. $\kappa_{\|}$maps (C) and $\kappa_{\perp}$ maps (D) of renal allograft. DKI= diffusion kurtosis imaging, $M K=$ mean kurtosis

artifacts, perfusion, inaccuracies of the fitting model, incomplete accounting for imaging gradient contributions to b-values, and noise (36-38). DKI of the body is particularly challenging due to heterogeneous body composition with resulting chemical shifts and susceptibility differences leading to image artifacts, as well as various physiological factors (e.g., breathing, heartbeat, blood flow) causing image degradation $(39,40)$.

Few studies have reported the application of DKI in the kidneys. Huang et al. (40) found that the medullary MK, $\kappa_{\perp}$, and $\kappa_{\|}$values are higher than those of the cortex in functioning native kidneys. The corticomedullary difference in these diffusion kurtosis metrics is consistent with the presence of radially-oriented vessels, tubules, and collecting ducts in the medulla (40). In contrast, Pentang et al. (41) reported that the medullary MK is lower than cortical MK. Kjølby et al. (42) introduced the fast DKI technique and showed that it can distinguish moderately fibrotic kidneys from healthy controls in a pre-clinical model. Importantly, this technique substantially reduces some of the previously mentioned challenges of DKI in the body by lowering the data requirement so that triggering and breath-hold techniques may be applied for the entire DKI acquisition within feasible scan time (42). Recently, Liu et al. (43) also observed that MK values increased with the progression of renal fibrosis and the deterioration of renal function in immunoglobulin A nephropathy patients and showed excellent discrimination in identifying the extent of fibrosis. The precise underlying meaning of the diffusional kurtosis metrics has not been fully understood, and DKI acquisition still needs to be optimized. Thus, more studies are necessary to investigate the potential of this technique to reveal additional information on pathological alterations in the kidneys.

\section{Blood 0xygen-Level-Dependent MRI}

Blood oxygen-level-dependent (BOLD) MRI allows noninvasive assessment of tissue oxygenation, which is particularly relevant for the kidneys as hypoxia is strongly implicated in both acute kidney injury and chronic kidney disease (44). BOLD MRI is based on the principle that blood deoxyhemoglobin has paramagnetic properties and shortens the $\mathrm{T} 2$ or $\mathrm{T}^{*}$ relaxation time, and the relative levels of deoxyhemoglobin versus oxyhemoglobin in the blood determines the signal intensity of tissue on T2or $\mathrm{T} 2{ }^{*}$-weighted images. The apparent relaxation rate denoted as $\mathrm{R} 2^{*}\left(1 / \mathrm{T} 2^{*}\right)$ is directly proportional to tissue 

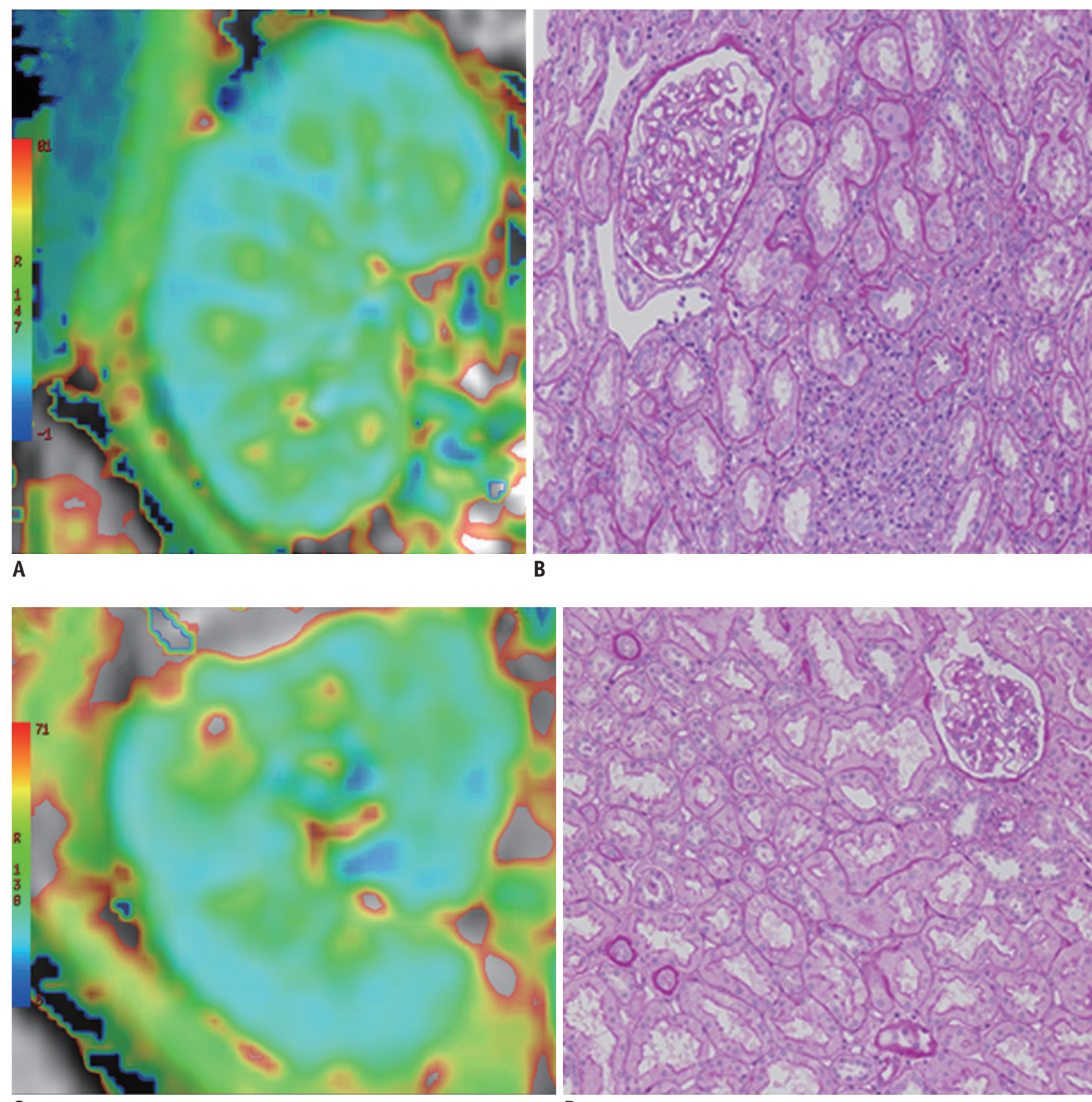

C

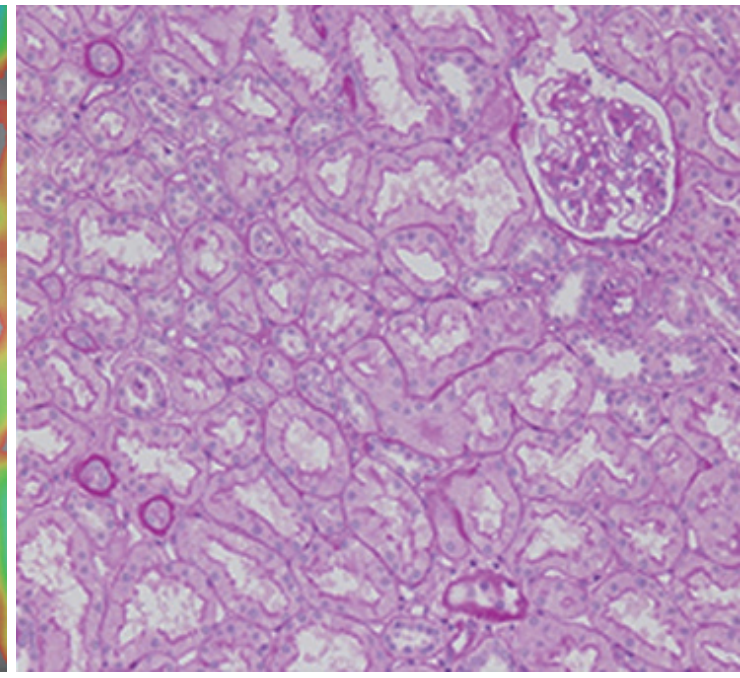

D

Fig. 4. Comparison of blood oxygen-level-dependent signals between patients with AR and good allograft function.

A, B. Images of 28-year-old woman with AR 7 months after transplantation (eGFR $\left.=86 \mathrm{~mL} / \mathrm{min} / 1.73 \mathrm{~m}^{2}\right)$. C, D. Images of 58 -year-old man with normal graft function 15 months after transplantation (eGFR $=72 \mathrm{~mL} / \mathrm{min} / 1.73 \mathrm{~m}^{2}$ ). Higher R2* values are calculated in medulla of normal functioning allograft compared with that with AR. Panel B shows AR on histology, while panel $\mathbf{D}$ shows histology of normally functioning allograft (periodic sciff-acid stain; original magnification, $\times 200$ ). AR = acute rejection

deoxyhemoglobin levels (45).

Numerous studies have shown that the medullary R2* is higher than the cortical R2* in functioning kidneys, likely reflecting the oxygen gradient from the cortex to the inner medulla, and have demonstrated that BOLD MRI can sensitively monitor changes in renal oxygenation modulated by physiological or pharmacologic challenges (14, 46-48). For example, BOLD MRI detected a significant increase in medullary oxygen bioavailability following water loading or furosemide administration with resultant inhibition of active solute reabsorption in medullary tubules (14). Similarly, the technique detected increased medullary oxygen bioavailability following the administration of angiotensin converting enzyme inhibitor or angiotensin receptor blocker with subsequent dilatation of glomerular arterioles and an increase in medullary blood supply (48). However, BOLD MRI cannot distinguish the changes in oxygenation caused by perfusion alterations from those attributed to oxygen consumption alterations.

With regard to renal allograft evaluation, prior 
studies have reported variable results of BOLD MRI for differentiating among etiologies of early allograft dysfunction (Fig. 4) (49-52). For example, Sadowski et al. (49) and Han et al. (50) found that the medullary R2* of allografts with AR was significantly lower than that of normally functioning allografts or allograft with ATN, while the cortical R2* of allografts with ATN was much higher than that of normal allografts. In contrast, Park et al. (51, 52) reported that BOLD MRI is limited in characterizing the cause of early renal allograft dysfunction. Djamali et al. (53) further assessed intra-renal oxygenation in patients with chronic allograft injury and found decreased medullary and cortical R2* levels when compared with values in healthy volunteers. It was hypothesized that the reduced oxygen extraction and consumption in chronic allograft injury lead to increased oxygen bioavailability (53). Seif et al. (54) recently demonstrated that stable $\mathrm{R} 2$ * values of the allografts were related to stable allograft function during the one-year follow-up period. Taken together, BOLD MRI allows noninvasive detection of changes in renal allograft oxygenation and shows promise in longitudinally monitoring allograft injury.

\section{Magnetic Resonance Perfusion Imaging}

Perfusion imaging to assess blood flow and perfusion deficits is an important part of renal allograft evaluation. However, perfusion imaging with gadolinium-based contrast materials places patients with impaired renal function at risk for nephrogenic systemic fibrosis (55). Additionally, recent studies have also raised concerns regarding gadolinium deposition in the brain following gadoliniumenhanced MRI $(56,57)$. Therefore, non-enhanced MRI techniques are gaining more attention as a safer alternative for perfusion imaging.

Arterial spin labeling (ASL) MRI uses blood as an endogenous contrast agent, allowing perfusion measurements without the administration of exogenous contrast. In ASL, the inflowing blood is selectively labeled to have an opposite magnetization compared with the tissue of interest. The signal difference between a labeled image (tag) and a non-labeled image (control) can be used to calculate tissue perfusion. As the signal difference is small, multiple acquisitions and signal averaging are necessary. ASL techniques are divided into two categories according to the labeling methods, namely continuous ASL and pulsed ASL. The former is not widely used in the clinical setting due to the high requirements on MRI hardware. Pulsed ASL, in contrast, has been applied clinically to investigate perfusion in various diseases. In pulsed ASL, magnetization vector exchange between the labeled blood and tissue is related to the time that the blood passes through the tissue. The calculation of the perfusion rate $f$ is based on the changes in $\mathrm{T} 1$ of the labeled blood after perfusion through the tissue of interest. Compared to contrastenhanced perfusion imaging, ASL is limited by a relatively lower SNR, longer scan time, and lower spatial resolution. Furthermore, quantification of perfusion with ASL can be influenced by several factors. For example, accelerated blood flow may impede the exchange rate between capillaries and tissue, leading to an underestimation of tissue perfusion. Additionally, in the context of renal allografts, the variations of renal cortical $\mathrm{T} 1$ values may also influence perfusion measurements $(58,59)$.

Multiple studies have demonstrated the potential of ASL in monitoring renal allograft perfusion (Fig. 5) (6064). For example, Lanzman et al. (61) found significantly reduced allograft perfusion, measured by ASL, in patients with acute allograft dysfunction. Artz et al. (63) reported a positive correlation between renal cortical perfusion and eGFR in both transplanted and native kidneys, which further supported the notion that glomerular filtration is regulated by renal blood flow. In that study, renal medullary perfusion measurements appeared to be less reproducible than renal cortical perfusion measurements by ASL, which may be related to the different controlling mechanisms of cortical and medullary blood flow, and the lower blood flow with lower SNR in the medulla. A recent ASL study demonstrated that patients with delayed graft function (DGF), which is associated with long-term impaired allograft function and graft loss, had significantly lower allograft perfusion than those with normal graft function. At the 12-month followup, DGF patients with subsequently improved allograft function had strikingly higher graft perfusion compared to those with persistent impairment of graft function (65). The observed perfusion decrease in allografts with acute or chronic rejection was shown to be closely related to inflammation, vascular lesions, and interstitial fibrosis (66).

Several studies have also investigated renal allografts using ASL combined with other functional MRI techniques $(67,68)$. For example, Heusch et al. (67) showed a significant correlation between allograft perfusion measured by ASL MRI and the fraction of pseudodiffusion derived from IVIM-MRI. Ren et al. (68) reported that the combination of 

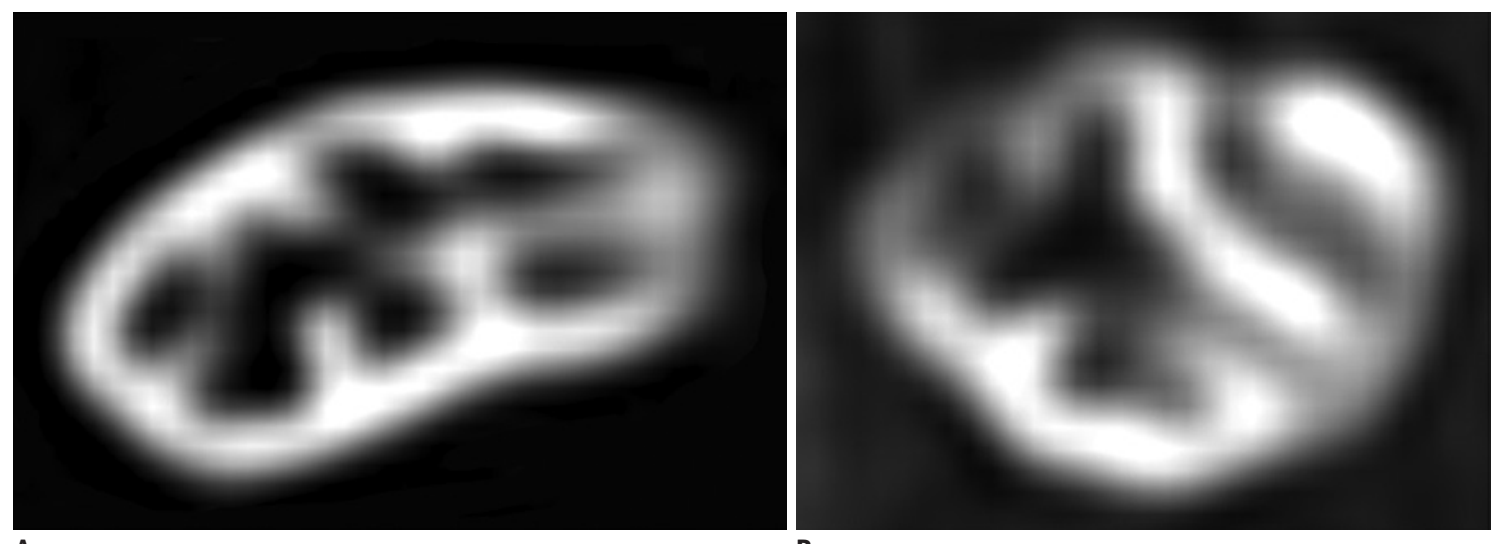

A

B
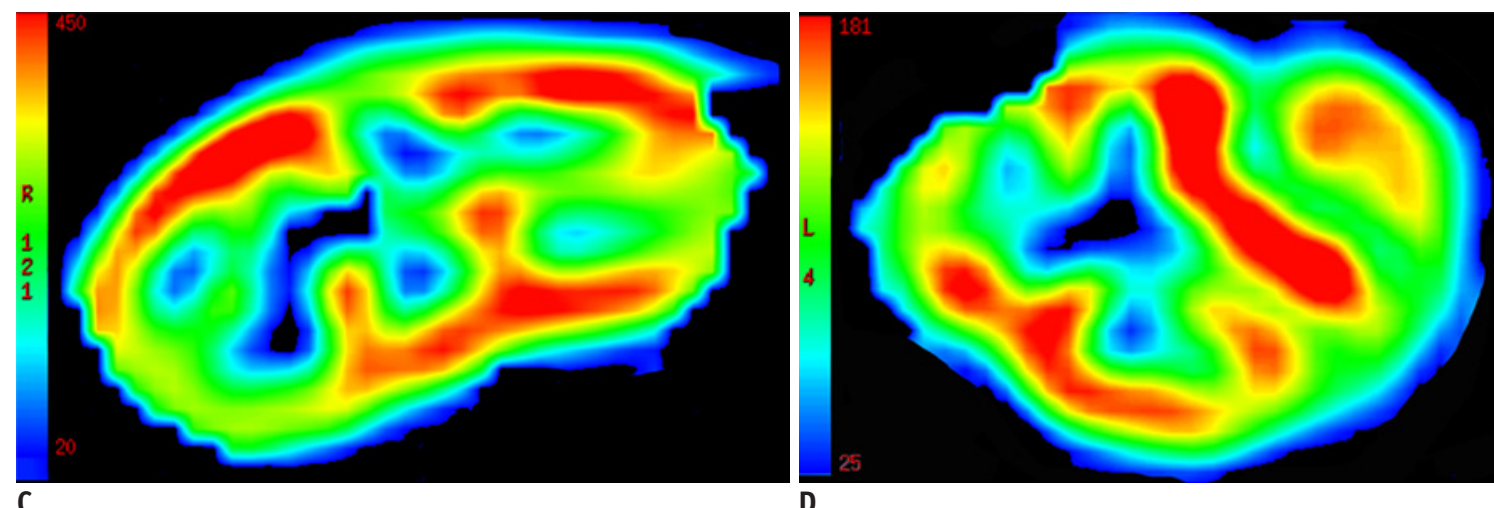

Fig. 5. Comparison of ASL perfusion between patients with good and poor renal allograft function.

A, C. Images from 35-year-old woman with good allograft function 14 years after transplantation $\left(\mathrm{eGFR}=100 \mathrm{~mL} / \mathrm{min} / 1.73 \mathrm{~m}{ }^{2}\right)$. B, D. Images from 31-year-old woman with poor function allograft 5 months after transplantation (eGFR $=45 \mathrm{~mL} / \mathrm{min} / 1.73 \mathrm{~m}^{2}$ ). A, B. ASL images of renal allograft; C, D color-coded ASL maps, where blue color represents low perfusion and red represents high perfusion. Lower perfusion values are shown in allograft with poor function. ASL= arterial spin labeling

ASL MRI and IVIM-DWI had a higher area under the receiver operating characteristic curve than that of ASL MRI alone for distinguishing allografts with impaired function from those with normal function.

In summary, ASL MRI is a promising non-contrast method for assessing renal allograft perfusion. More studies are, however, needed to demonstrate its clinical value in noninvasively monitoring allograft injury and predicting outcome.

\section{Magnetic Resonance Elastography}

Renal fibrosis, characterized by the abnormal accumulation of macrophages, myofibroblasts and the deposition of fibrotic interstitial matrix, is the common final pathway for various forms of kidney disease. As with native kidneys, the long-term outcome of renal allografts is largely predicted by the degree of interstitial fibrosis (69-71).

Magnetic resonance elastography (MRE) can noninvasively interrogate tissue stiffness by imaging the viscoelastic properties of tissues based on their response to external mechanical vibration. MRE is performed by using an external vibration source to generate low-frequency mechanical waves in tissues of interest, imaging the propagating waves using a phase-contrast MRI technique, and then processing the wave information to generate quantitative images of tissue stiffness (Fig. 6). There are several analysis techniques used for measuring the shear mechanical properties of tissues, including wavelength estimation (most commonly used in the kidneys), direct inversion, and nonlinear inversion. Several MRE metrics are obtained through wavelength estimation, including the elastic shear modulus $G$ which represents a simple and intuitive measurement of the wavelength, and complex shear modulus $\mathrm{G}^{*}$ which determines both the elastic and viscous (i.e., viscoelastic) tissue properties. The magnitude $\left|\mathrm{G}^{*}\right|$ of the complex modulus $G^{*}$ of the tissue is most similar to information provided by manual palpation and reflects the total tissue 


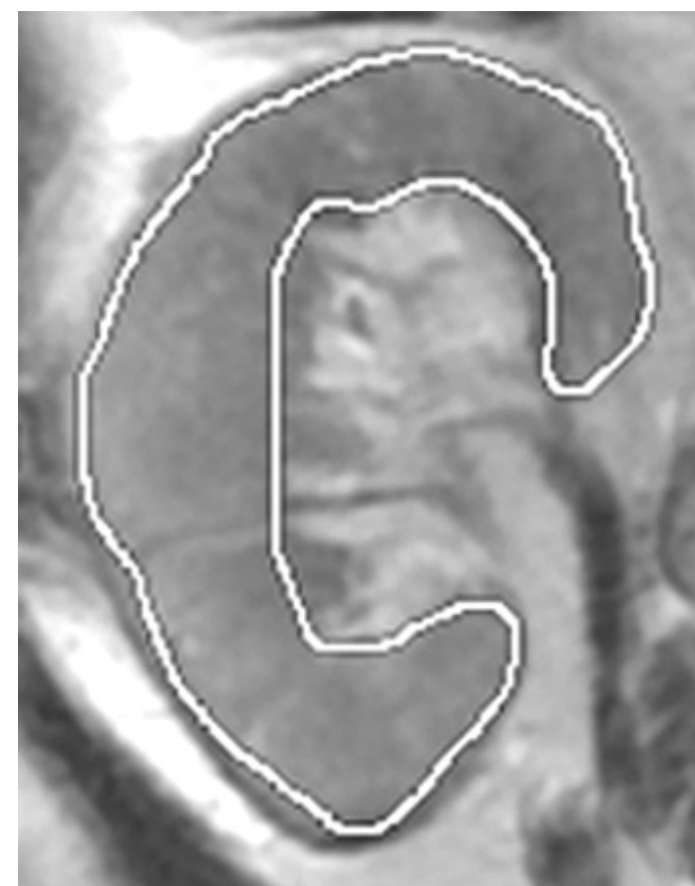

A

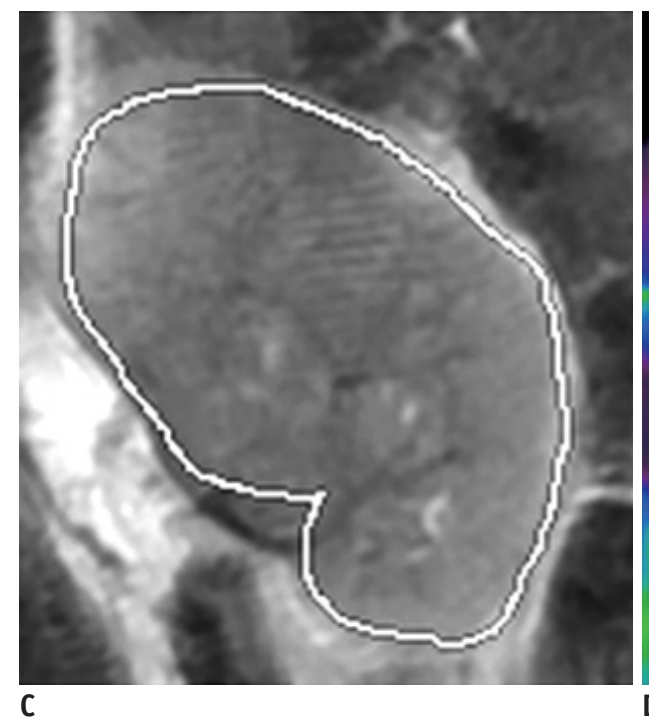

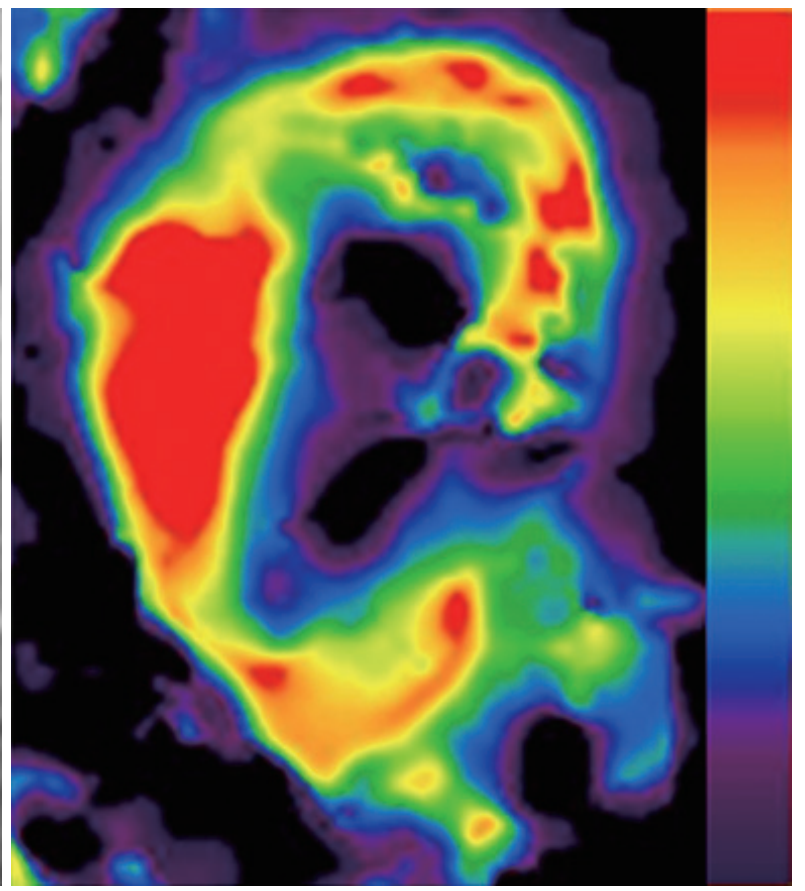

B

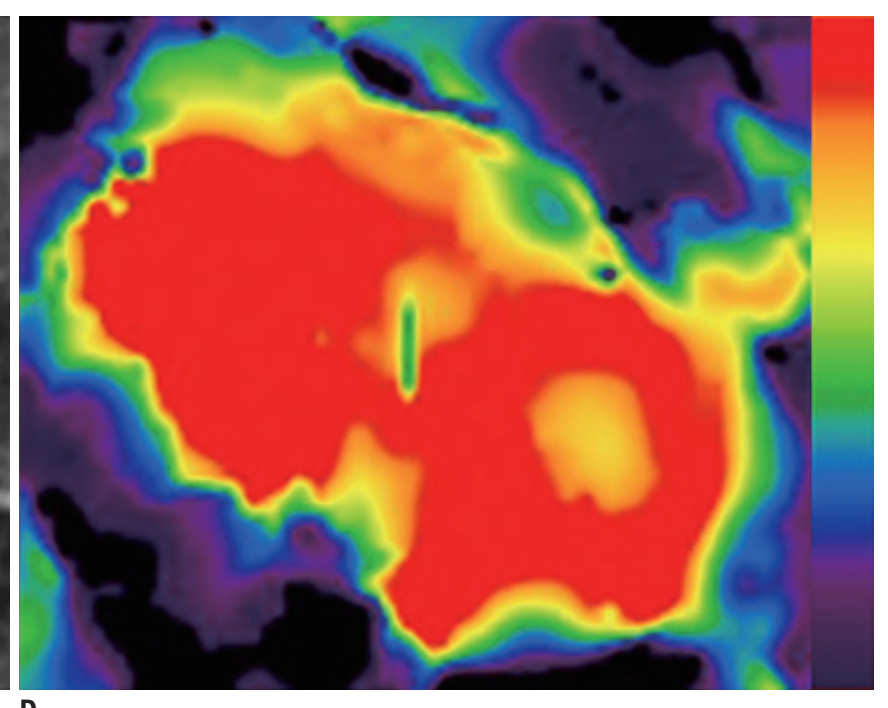

Fig. 6. MRE images demonstrate heterogeneous distribution of stiffness in kidney.

A, B. Images from 49-year-old man with poor allograft function 12 years after transplantation (eGFR = $\left.15 \mathrm{~mL} / \mathrm{min} / 1.73 \mathrm{~m}^{2}\right)$. C, D. Images from 32-year-old man with good functioning allograft 4 years after transplantation (eGFR $\left.=89 \mathrm{~mL} / \mathrm{min} / 1.73 \mathrm{~m}^{2}\right)$. A, C. Anatomic T2 weighted images of kidney allografts; B, D MRE stiffness maps, where blue color represents softer tissue and red represents stiffer tissue. MRE= magnetic resonance elastography

response to shear wave. MRE is already used widely for imaging liver fibrosis in the clinic. It has also been applied to several other organs, including the kidney, spleen, brain, pancreas, and uterus (72-75).

Lee et al. (76) performed the initial studies of MRE in renal allografts in 11 subjects and did not find a significant correlation between stiffness measured by MRE and fibrosis assessed by histopathology. A subsequent study by Marticorena Garcia et al. (77) reported that the renal stiffness measured by MRE was significantly lower in nonfunctioning renal allografts compared to that in functioning allografts and was correlated with glomerular filtration rate and the resistive index (77). In contrast, a recent study by Kirpalani et al. (78) demonstrated a moderately positive correlation between allograft stiffness and biopsy-derived fibrosis score. These discrepant results 
may be explained by the fact that the allograft stiffness measured by MRE may reflect a combination of fibrosis and perfusion pressure. For example, in a poorly functioning allograft, the presence of fibrosis can increase stiffness while the reduced perfusion can reduce stiffness. Therefore, MRE-measured stiffness may not directly correlate with the degree of fibrosis at histology. Incorporation of perfusion measures may improve the interpretation of observed stiffness measured by MRE and its relationship to histological fibrosis.

\section{Magnetization Transfer Imaging}

Magnetization transfer imaging (MTI) can investigate the macromolecule content in tissue based on the interactions of protons from free water and macromolecules. In MTI, off-resonance radiofrequency (RF) pulses are applied to saturate the macromolecular protons and then to acquire the free water proton magnetic resonance (MR) signal at a time sufficient for proton exchange between the two proton pools. The technique is sensitive to the presence of large and immobile macromolecules, such as collagens, in tissues, and can be quantified by measuring signal intensity changes with or without RF saturation, termed as magnetization transfer ratio (MTR). In the context of the kidneys, it provides a novel strategy to evaluate the presence of fibrosis (79).

At present, there are only a limited number of studies on MTI of kidneys. Kline et al. (80) utilized MTI to investigate tissue remodeling in a murine model of autosomal dominant polycystic kidney disease and demonstrated a high correlation between MTR and histology-derived cystic and fibrotic changes in the kidneys. In a model of unilateral ureteral obstruction, Wang et al. (81) showed that the renal MTR decreased significantly in the obstructed kidneys. More recently, Jiang et al. (82) showed that MTI at a high field strength (16.4T) can be used to measure and longitudinally monitor the progression of renal fibrosis in mice with unilateral renal artery stenosis. There was a good correlation between MTR and fibrosis measured ex vivo. Nevertheless, factors other than fibrosis, such as reduced renal perfusion, accumulation of other extracellular proteins, and inflammatory cell infiltration might also affect MTR measurements, and further studies are needed to investigate their influence on MTI. In the same study, the investigators also found that regions with excessive collagen deposition on MTR maps also exhibited hypoxia on R2* maps from
BOLD MRI and that the hypoxia appeared earlier and was more extensive than renal fibrosis. These findings suggest that BOLD MRI can provide complementary information to MTI, and that hypoxic but nonfibrotic regions may represent zones of more readily reversible renal injury (82). The same group of investigators further demonstrated the feasibility of MTI for detecting renal fibrosis at clinical field strength (3T) in a swine model of renal artery stenosis (83). This suggests that MTI may potentially be clinically applicable and useful for detection and monitoring of renal pathology, including renal allograft injury.

\section{Future Perspectives}

Although functional MRI techniques enable noninvasive quantitative assessment of allograft injury and are gradually increasing their clinical position, knowledge of the application of functional MRI techniques in allograft injury is still insufficient and urgent. In addition, there are many unsolved problems in this field. First, the sample size of most currently published studies was not sufficient, and the studies mostly demonstrated the feasibility and reproducibility of functional MRI techniques in the evaluation of allograft injury. Large clinical studies are urgently needed. Second, the correlation of histopathologic outcomes and quantitative functional MR parameters needs to be further defined to more precisely understand and interpret the functional MRI findings. Third, some functional MR techniques in the kidney, such as DKI, MRE, and MTI, need to be further optimized and the precise underlying meaning of the corresponding parameters has not been fully understood. Finally, the application value of single functional MRI techniques in allograft injury is limited. The combination of multiple functional MRI evaluations for allograft injury and the potential link among different parameters remains to be explored. Future studies should focus on these unsolved problems and provide valid evidence to the public.

\section{CONCLUSION}

In conclusion, the various functional MRI techniques discussed above have shown promise for noninvasive monitoring of renal allograft injury, which is essential for guiding appropriate interventions to delay or prevent irreversible damage. In particular, advanced functional MR techniques provide new ways for quantification of 
renal fibrosis, which predicts poor allograft outcome. More detailed assessments are needed to translate these novel techniques from research tools into clinical practices to improve the care of patients with renal allografts.

\section{Conflicts of Interest}

The authors have no potential conflicts of interest to disclose.

\author{
ORCID iDs \\ Long Jiang Zhang \\ https://orcid.org/0000-0002-6664-7224 \\ Yuan Meng Yu \\ https://orcid.org/0000-0003-3610-0962 \\ Qian Qian Ni \\ https://orcid.org/0000-0003-4230-5059 \\ Zhen Jane Wang \\ https://orcid.org/0000-0002-2065-5296 \\ Meng Lin Chen \\ https://orcid.org/0000-0002-8129-1684
}

\section{REFERENCES}

1. Cavallo MC, Sepe V, Conte F, Abelli M, Ticozzelli E, Bottazzi A, et al. Cost-effectiveness of kidney transplantation from DCD in Italy. Transplant Proc 2014;46:3289-3296

2. Zhang L, Wang F, Wang L, Wang W, Liu B, Liu J, et al. Prevalence of chronic kidney disease in China: a crosssectional survey. Lancet 2012;379:815-822

3. Liu ZH. Nephrology in China. Nat Rev Nephrol 2013;9:523-528

4. Aubert 0 , Kamar N, Vernerey D, Viglietti D, Martinez F, DuongVan-Huyen JP, et al. Long term outcomes of transplantation using kidneys from expanded criteria donors: prospective, population based cohort study. BMJ 2015;351:h3557

5. Goldberg RJ, Weng FL, Kandula P. Acute and chronic allograft dysfunction in kidney transplant recipients. Med Clin North Am 2016;100:487-503

6. Earley A, Miskulin D, Lamb EJ, Levey AS, Uhlig K. Estimating equations for glomerular filtration rate in the era of creatinine standardization: a systematic review. Ann Intern Med 2012;156:785-795, W-270, W-271, W-272, W-273, W-274, W-275, W-276, W-277, W-278

7. Moreno CC, Mittal PK, Ghonge NP, Bhargava P, Heller MT. Imaging complications of renal transplantation. Radiol Clin North Am 2016;54:235-249

8. Azancot MA, Moreso F, Salcedo M, Cantarell C, Perello M, Torres IB, et al. The reproducibility and predictive value on outcome of renal biopsies from expanded criteria donors. Kidney Int 2014;85:1161-1168

9. Wang YT, Li YC, Yin LL, Pu H, Chen JY. Functional assessment of transplanted kidneys with magnetic resonance imaging. World J Radiol 2015;7:343-349

10. Ljimani A, Wittsack HJ. Functional MRI in transplanted kidneys. Abdom Radiol (NY) 2018;43:2615-2624

11. Baliyan V, Das CJ, Sharma R, Gupta AK. Diffusion weighted imaging: technique and applications. World J Radiol 2016;8:785-798

12. Eisenberger U, Thoeny HC, Binser T, Gugger M, Frey FJ, Boesch $C$, et al. Evaluation of renal allograft function early after transplantation with diffusion-weighted MR imaging. Eur Radiol 2010;20:1374-1383

13. Kaul A, Sharma RK, Gupta RK, Lal H, Yadav A, Bhadhuria D, et al. Assessment of allograft function using diffusion-weighted magnetic resonance imaging in kidney transplant patients. Saudi J Kidney Dis Transpl 2014;25:1143-1147

14. Thoeny HC, Zumstein D, Simon-Zoula S, Eisenberger U, De Keyzer F, Hofmann L, et al. Functional evaluation of transplanted kidneys with diffusion-weighted and BOLD MR imaging: initial experience. Radiology 2006;241:812-821

15. Vermathen P, Binser T, Boesch C, Eisenberger U, Thoeny $\mathrm{HC}$. Three-year follow-up of human transplanted kidneys by diffusion-weighted MRI and blood oxygenation level-dependent imaging. J Magn Reson Imaging 2012;35:1133-1138

16. Palmucci S, Mauro LA, Veroux P, Failla G, Milone P, Ettorre GC, et al. Magnetic resonance with diffusion-weighted imaging in the evaluation of transplanted kidneys: preliminary findings. Transplant Proc 2011;43:960-966

17. Palmucci S, Mauro LA, Failla G, Foti PV, Milone P, Sinagra N, et al. Magnetic resonance with diffusion-weighted imaging in the evaluation of transplanted kidneys: updating results in 35 patients. Transplant Proc 2012;44:1884-1888

18. Eisenberger U, Binser T, Thoeny HC, Boesch C, Frey FJ, Vermathen $\mathrm{P}$. Living renal allograft transplantation: diffusionweighted MR imaging in longitudinal follow-up of the donated and the remaining kidney. Radiology 2014;270:800-808

19. Kuai ZX, Liu WY, Zhu YM. Effect of multiple perfusion components on pseudo-diffusion coefficient in intravoxel incoherent motion imaging. Phys Med Biol 2017;62:8197-8209

20. Thoeny HC, De Keyzer F. Diffusion-weighted MR imaging of native and transplanted kidneys. Radiology 2011;259:25-38

21. Xie Y, Li Y, Wen J, Li X, Zhang Z, Li J, et al. Functional evaluation of transplanted kidneys with reduced field-ofview diffusion-weighted imaging at 3 T. Korean $\mathrm{J}$ Radiol 2018;19:201-208

22. Sulkowska K, Palczewski P, Wojcik D, Ciszek M, SankoResmer J, Wojtowicz J, et al. Intravoxel incoherent motion imaging in monitoring the function of kidney allograft. Acta Radiol 2018 Sep 23 [Epub ahead of print]. http://doi. org/10.1177/0284185118802598

23. Mori S, Zhang J. Principles of diffusion tensor imaging and its applications to basic neuroscience research. Neuron 2006;51:527-539

24. Morrell GR, Zhang JL, Lee VS. Magnetic resonance imaging of the fibrotic kidney. J Am Soc Nephrol 2017;28:2564-2570 
25. Kido A, Kataoka M, Yamamoto A, Nakamoto Y, Umeoka S, Koyama $T$, et al. Diffusion tensor MRI of the kidney at 3.0 and 1.5 tesla. Acta Radiol 2010;51:1059-1063

26. Notohamiprodjo M, Dietrich 0, Horger W, Horng A, Helck $A D$, Herrmann KA, et al. Diffusion tensor imaging (DTI) of the kidney at 3 tesla-feasibility, protocol evaluation and comparison to 1.5 tesla. Invest Radiol 2010;45:245-254

27. Cheung JS, Fan SJ, Chow AM, Zhang J, Man K, Wu EX. Diffusion tensor imaging of renal ischemia reperfusion injury in an experimental model. NMR Biomed 2010;23:496-502

28. Deger E, Celik A, Dheir H, Turunc V, Yardimci A, Torun M, et al. Rejection evaluation after renal transplantation using MR diffusion tensor imaging. Acta Radiol 2018;59:876-883

29. Hueper K, Khalifa AA, Bräsen JH, Vo Chieu VD, Gutberlet $M$, Wintterle $S$, et al. Diffusion-weighted imaging and diffusion tensor imaging detect delayed graft function and correlate with allograft fibrosis in patients early after kidney transplantation. J Magn Reson Imaging 2016;44:112-121

30. Palmucci S, Cappello G, Attinà G, Foti PV, Siverino R0, Roccasalva $F$, et al. Diffusion weighted imaging and diffusion tensor imaging in the evaluation of transplanted kidneys. Eur J Radiol Open 2015;2:71-80

31. Li Y, Lee MM, Worters PW, MacKenzie JD, Laszik Z, Courtier JL. Pilot study of renal diffusion tensor imaging as a correlate to histopathology in pediatric renal allografts. AJR Am J Roentgenol 2017;208:1358-1364

32. Kaimori JY, Isaka Y, Hatanaka M, Yamamoto S, Ichimaru N, Fujikawa A, et al. Diffusion tensor imaging MRI with spinecho sequence and long-duration measurement for evaluation of renal fibrosis in a rat fibrosis model. Transplant Proc 2017; $49: 145-152$

33. Hueper K, Gutberlet M, Rodt T, Gwinner W, Lehner F, Wacker $\mathrm{F}$, et al. Diffusion tensor imaging and tractography for assessment of renal allograft dysfunction-initial results. Eur Radiol 2011;21:2427-2433

34. Lanzman RS, Ljimani A, Pentang G, Zgoura P, Zenginli $H$, Kropil $P$, et al. Kidney transplant: functional assessment with diffusion-tensor MR imaging at 3T. Radiology 2013;266:218225

35. Fan WJ, Ren T, Li Q, Zuo PL, Long MM, Mo CB, et al. Assessment of renal allograft function early after transplantation with isotropic resolution diffusion tensor imaging. Eur Radiol 2016;26:567-575

36. Fukunaga I, Hori M, Masutani Y, Hamasaki N, Sato S, Suzuki $Y$, et al. Effects of diffusional kurtosis imaging parameters on diffusion quantification. Radiol Phys Technol 2013;6:343-348

37. Jensen JH, Helpern JA. MRI quantification of nongaussian water diffusion by kurtosis analysis. NMR Biomed 2010;23:698-710

38. Raab P, Hattingen E, Franz K, Zanella FE, Lanfermann H. Cerebral gliomas: diffusional kurtosis imaging analysis of microstructural differences. Radiology 2010;254:876-881

39. Giannelli M, Toschi N. On the use of trace-weighted images in body diffusional kurtosis imaging. Magn Reson Imaging
2016;34:502-507

40. Huang Y, Chen X, Zhang Z, Yan L, Pan D, Liang C, et al. MRI quantification of non-gaussian water diffusion in normal human kidney: a diffusional kurtosis imaging study. NMR Biomed 2015;28:154-161

41. Pentang G, Lanzman RS, Heusch P, Müller-Lutz A, Blondin D, Antoch G, et al. Diffusion kurtosis imaging of the human kidney: a feasibility study. Magn Reson Imaging 2014;32:413-420

42. Kjølby BF, Khan AR, Chuhutin A, Pedersen L, Jensen JB, Jakobsen $S$, et al. Fast diffusion kurtosis imaging of fibrotic mouse kidneys. NMR Biomed 2016;29:1709-1719

43. Liu $Y$, Zhang GM, Peng X, Wen Y, Ye W, Zheng $K$, et al. Diffusional kurtosis imaging in assessing renal function and pathology of IgA nephropathy: a preliminary clinical study. Clin Radiol 2018;73:818-826

44. Venkatachalam MA, Griffin KA, Lan R, Geng H, Saikumar P, Bidani AK. Acute kidney injury: a springboard for progression in chronic kidney disease. Am J Physiol Renal Physiol 2010;298:F1078-F1094

45. Li LP, Halter S, Prasad PV. Blood oxygen level-dependent MR imaging of the kidneys. Magn Reson Imaging Clin N Am 2008; 16:613-625

46. Malvezzi P, Bricault I, Terrier N, Bayle F. Evaluation of intrarenal oxygenation by blood oxygen level-dependent magnetic resonance imaging in living kidney donors and their recipients: preliminary results. Transplant Proc 2009;41:641-644

47. Oostendorp M, de Vries EE, Slenter JM, Peutz-Kootstra CJ, Snoeijs MG, Post MJ, et al. MRI of renal oxygenation and function after normothermic ischemia-reperfusion injury. NMR Biomed 2011;24:194-200

48. Niles DJ, Artz NS, Djamali A, Sadowski EA, Grist TM, Fain SB. Longitudinal assessment of renal perfusion and oxygenation in transplant donor-recipient pairs using arterial spin labeling and blood oxygen level-dependent magnetic resonance imaging. Invest Radiol 2016;51:113-120

49. Sadowski EA, Fain SB, Alford SK, Korosec FR, Fine J, Muehrer $R$, et al. Assessment of acute renal transplant rejection with blood oxygen level-dependent MR imaging: initial experience. Radiology 2005;236:911-919

50. Han F, Xiao W, Xu Y, Wu J, Wang Q, Wang H, et al. The significance of BOLD MRI in differentiation between renal transplant rejection and acute tubular necrosis. Nephrol Dial Transplant 2008;23:2666-2672

51. Park SY, Kim CK, Park BK, Huh W, Kim SJ, Kim B. Evaluation of transplanted kidneys using blood oxygenation leveldependent MRI at $3 \mathrm{~T}$ : a preliminary study. AJR Am J Roentgenol 2012;198:1108-1114

52. Park SY, Kim CK, Park BK, Kim SJ, Lee S, Huh W. Assessment of early renal allograft dysfunction with blood oxygenation level-dependent MRI and diffusion-weighted imaging. Eur J Radiol 2014;83:2114-2121

53. Djamali A, Sadowski EA, Muehrer RJ, Reese S, Smavatkul C, Vidyasagar A, et al. BOLD-MRI assessment of intrarenal oxygenation and oxidative stress in patients with chronic 
kidney allograft dysfunction. Am J Physiol Renal Physiol 2007;292:F513-F522

54. Seif M, Eisenberger U, Binser T, Thoeny HC, Krauer F, Rusch $A$, et al. Renal blood oxygenation level-dependent imaging in longitudinal follow-up of donated and remaining kidneys. Radiology 2016;279:795-804

55. Kuo PH, Kanal E, Abu-Alfa AK, Cowper SE. Gadoliniumbased MR contrast agents and nephrogenic systemic fibrosis. Radiology 2007;242:647-649

56. Guo BJ, Yang ZL, Zhang LJ. Gadolinium deposition in brain: current scientific evidence and future perspectives. Front Mol Neurosci 2018;11:335

57. Boyken J, Niendorf T, Flemming B, Seeliger E. Gadolinium deposition in the brain after contrast-enhanced MRI: are the data valid? Radiology 2018;288:630-632

58. Ho ML. Arterial spin labeling: clinical applications. J Neuroradiol 2018;45:276-289

59. Havsteen I, Damm Nybing J, Christensen H, Christensen AF. Arterial spin labeling: a technical overview. Acta Radiol 2018;59:1232-1238

60. Sadowski EA, Djamali A, Wentland AL, Muehrer R, Becker BN, Grist TM, et al. Blood oxygen level-dependent and perfusion magnetic resonance imaging: detecting differences in oxygen bioavailability and blood flow in transplanted kidneys. Magn Reson Imaging 2010;28:56-64

61. Lanzman RS, Wittsack HJ, Martirosian P, Zgoura P, Bilk P, Kröpil $P$, et al. Quantification of renal allograft perfusion using arterial spin labeling MRI: initial results. Eur Radiol 2010;20:1485-1491

62. Artz NS, Sadowski EA, Wentland AL, Djamali A, Grist TM, Seo S, et al. Reproducibility of renal perfusion MR imaging in native and transplanted kidneys using non-contrast arterial spin labeling. J Magn Reson Imaging 2011;33:1414-1421

63. Artz NS, Sadowski EA, Wentland AL, Grist TM, Seo S, Djamali A, et al. Arterial spin labeling MRI for assessment of perfusion in native and transplanted kidneys. Magn Reson Imaging 2011;29:74-82

64. Heusch P, Wittsack HJ, Blondin D, Ljimani A, Nguyen-Quang M, Martirosian $P$, et al. Functional evaluation of transplanted kidneys using arterial spin labeling MRI. J Magn Reson Imaging 2014;40:84-89

65. Hueper K, Gueler F, Bräsen JH, Gutberlet M, Jang MS, Lehner $F$, et al. Functional MRI detects perfusion impairment in renal allografts with delayed graft function. Am J Physiol Renal Physiol 2015;308:F1444-F1451

66. Hueper K, Schmidbauer M, Thorenz A, Bräsen JH, Gutberlet M, Mengel $M$, et al. Longitudinal evaluation of perfusion changes in acute and chronic renal allograft rejection using arterial spin labeling in translational mouse models. J Magn Reson Imaging 2017;46:1664-1672

67. Heusch P, Wittsack HJ, Heusner T, Buchbender C, Quang MN, Martirosian $\mathrm{P}$, et al. Correlation of biexponential diffusion parameters with arterial spin-labeling perfusion MRI: results in transplanted kidneys. Invest Radiol 2013;48:140-144
68. Ren T, Wen CL, Chen LH, Xie SS, Cheng Y, Fu YX, et al. Evaluation of renal allografts function early after transplantation using intravoxel incoherent motion and arterial spin labeling MRI. Magn Reson Imaging 2016;34:908-914

69. Strupler M, Hernest M, Fligny C, Martin JL, Tharaux PL, Schanne-Klein MC. Second harmonic microscopy to quantify renal interstitial fibrosis and arterial remodeling. J Biomed Opt 2008;13:054041

70. Park WD, Griffin MD, Cornell LD, Cosio FG, Stegall MD. Fibrosis with inflammation at one year predicts transplant functional decline. J Am Soc Nephrol 2010;21:1987-1997

71. Costa JS, Alves R, Sousa V, Marinho C, Romaozinho C, Santos L, et al. Fibrogenesis in kidney transplant: dysfunction progress biomarkers. Transplant Proc 2017; 49:787-791

72. Yin M, Kolipaka A, Woodrum DA, Glaser KJ, Romano AJ, Manduca $A$, et al. Hepatic and splenic stiffness augmentation assessed with MR elastography in an in vivo porcine portal hypertension model. J Magn Reson Imaging 2013;38:809-815

73. Jiang X, Asbach P, Streitberger KJ, Thomas A, Hamm B, Braun $J$, et al. In vivo high-resolution magnetic resonance elastography of the uterine corpus and cervix. Eur Radiol 2014;24:3025-3033

74. Dittmann F, Hirsch S, Tzschätzsch H, Guo J, Braun J, Sack I. In vivo wideband multifrequency MR elastography of the human brain and liver. Magn Reson Med 2016;76:1116-1126

75. Hiscox LV, Johnson CL, Barnhill E, McGarry MD, Huston J, van Beek EJ, et al. Magnetic resonance elastography (MRE) of the human brain: technique, findings and clinical applications. Phys Med Biol 2016;61:R401-R437

76. Lee CU, Glockner JF, Glaser KJ, Yin M, Chen J, Kawashima $A$, et al. MR elastography in renal transplant patients and correlation with renal allograft biopsy: a feasibility study. Acad Radiol 2012;19:834-841

77. Marticorena Garcia SR, Fischer T, Dürr M, Gültekin E, Braun J, Sack I, et al. Multifrequency magnetic resonance elastography for the assessment of renal allograft function. Invest Radiol 2016;51:591-595

78. Kirpalani A, Hashim E, Leung G, Kim JK, Krizova A, Jothy S, et al. Magnetic resonance elastography to assess fibrosis in kidney allografts. Clin J Am Soc Nephrol 2017;12:1671-1679

79. Martens MH, Lambregts DM, Papanikolaou N, Heijnen LA, Riedl RG, zur Hausen $A$, et al. Magnetization transfer ratio: a potential biomarker for the assessment of postradiation fibrosis in patients with rectal cancer. Invest Radiol 2014;49:29-34

80. Kline TL, Irazabal MV, Ebrahimi B, Hopp K, Udoji KN, Warner $J D$, et al. Utilizing magnetization transfer imaging to investigate tissue remodeling in a murine model of autosomal dominant polycystic kidney disease. Magn Reson Med 2016;75:1466-1473

81. Wang F, Jiang R, Takahashi K, Gore J, Harris RC, Takahashi T, et al. Longitudinal assessment of mouse renal injury using high-resolution anatomic and magnetization transfer MR imaging. Magn Reson Imaging 2014;32:1125-1132 
82. Jiang K, Ferguson CM, Ebrahimi B, Tang H, Kline $T L$, Burningham TA, et al. Noninvasive assessment of renal fibrosis with magnetization transfer MR imaging: validation and evaluation in murine renal artery stenosis. Radiology 2017;283:77-86
83. Jiang K, Ferguson CM, Woollard JR, Zhu X, Lerman LO. Magnetization transfer magnetic resonance imaging noninvasively detects renal fibrosis in swine atherosclerotic renal artery stenosis at 3.0 T. Invest Radiol 2017;52:686-692 